\title{
Effectiveness of Motivationally Tailored Interventions on Cervical Cancer Screening: A Systematic Review and Meta-analysis
}

\author{
Parvin Pourebrahim-Alamdari ${ }^{\circledR}{ }^{\oplus}$, Esmat Mehrabi $^{2}$, Neda Nikkhesal ${ }^{3}$, Roghaiyeh Nourizadeh ${ }^{2 *}$, Khalil $^{2}$ \\ Esmaeilpour ${ }^{4}$, Saeed Mousavi ${ }^{5}$
}

\begin{abstract}
Objectives: Cervical cancer is preventable through cervical cancer screening. People may be unwilling to take screening tests when they are healthy, and performing regular screening tests largely depends on motivational factors. Accordingly, the present study aimed to investigate the effectiveness of motivationally tailored interventions on women's cervical cancer screening. Materials and Methods: In this systematic review, the electronic databases of the Cochrane Library, Web of Science, PubMed, Scopus, Embase, and Google Scholar were searched for all interventional studies (i.e., trials, pre- and post-test, or quasi-experimental ones) published before 2019. Then, the Cochrane tool was implemented to evaluate the quality of trial studies (7 articles).

Results: This systematic review study included 7 articles with 1337 female participants. The result of our study showed that different motivational interventions (Mls) (i.e., face-to-face interviews, consultation sessions or calls, and educational programs) can effectively improve cervical cancer screening behavior in women.

Conclusions: Overall, motivational interventions (MIs) seem to be effective in cervical cancer screening.

Keywords: Motivational intervention, Counseling, Motivational interview, Cervical cancer screening, Pap smear, Protection motivation theory
\end{abstract}

\section{Introduction}

Cervical cancer is one of the major causes of disability adjustment years of women in developing countries (1). Approximately $87 \%$ of deaths from cervical cancer occur in less-developed countries. Among all malignant tumors, cervical cancer is one of the cancers that can be effectively controlled by organized screening programs. In this regard, Pap smear is a simple and cost-effective test for cervical cancer screening $(2,3)$. It is reported that a regular Pap smear can reduce mortality by up to $80 \%$ (4). A study in Iran demonstrated that only $20 \%$ of women have never had this test, about two-third (68.7\%) of them had this test only once in their life, and only $11.3 \%$ of them had taken a Pap test at standard intervals (5).

People may indicate an unwillingness to take screening tests when they are in good health. In addition, performing regular screening tests heavily relies on motivational factors. Thus, motivational intervention (MI) is one of the ways to modify health-related behaviors. This method was introduced in 1983 by William Miller to change the drinking habit of alcoholic people. Further, it is a client-centered approach and helps identify and resolve behavioral ambiguity and reinforce the intrinsic motivation by discovering, identifying, and finding a specific solution $(6,7)$. There are reasons for the tendency to use MI in comparison to conventional methods in health-related practice (8). MIs directly eliminate resistance to change. Furthermore, they are flexible and can be used in combination with other treatments. Moreover, evidence supports the efficacy and impact of MI on physical and mental health issues. Finally, MI can be easily learned, and significant therapeutic effects can be achieved in a few sessions $(9,10)$. Nevertheless, there is a lack of systematic reviews about the effectiveness of MIs on cervical cancer screening. Therefore, this study sought to systematically review the published intervention studies that examined the efficacy of MIs for improving cervical cancer screening among women.

\section{Materials and Methods}

This systematic review was conducted to determine the effectiveness of motivationally tailored interventions on cervical cancer screening behavior in women.

\section{Search Strategy}

All published articles before September 2019 were assessed in this study. To this end, articles were reviewed from several electronic databases (i.e., Cochrane 


\section{Key Messages}

- This review prepared enough evidence to support or refute that implementation MI can improve women's cervical cancer prevention behaviors.

- The MI strategies can improve and facilitate making decisions on change among women and result in an increase in the regulated cervical cancer screening uptake.

- Further randomized controlled trials are needed to study the effect of different strategies that can be more effective on health-related preventive behaviors.

Library, Web of Science, PubMed, Scopus, Embase, and Google Scholar). The search terms were 'motivational interviewing', 'counseling,' 'cervical cancer screening,' 'Pap test', 'randomized clinical trial', 'protection motivation theory', and the 'experimental and quasi-experimental study'. The search was limited by language (English) and method (i.e., clinical trial, randomized controlled clinical trial, and experimental and quasi-experimental studies). Further searches were carried out with the same strategy among dissertations, books, and available unpublished articles. Furthermore, resources were managed using Endnote software. Then, the title and abstract of the related articles were studied for selecting the corpus. This search yielded 216 abstracts, and finally, 7 articles were selected and assessed based on the aim of the study. The Cochrane tool was used to evaluate the quality of trial studies. This tool examines studies in six steps, the details of which are shown in Table 1 and Figure 1. Additionally, the characteristics and the judgment methods of the articles are presented in Table S1 (See Supplementary file 1). Eventually, the risk of bias rating for the included studies is displayed in Figures 2 and 3.

\section{Results}

This systematic review included 7 articles with 1337 female participants. Table S1 summarizes the characteristics and
Identification of Related Articles

Studies identified through database searches $(n=3152)$

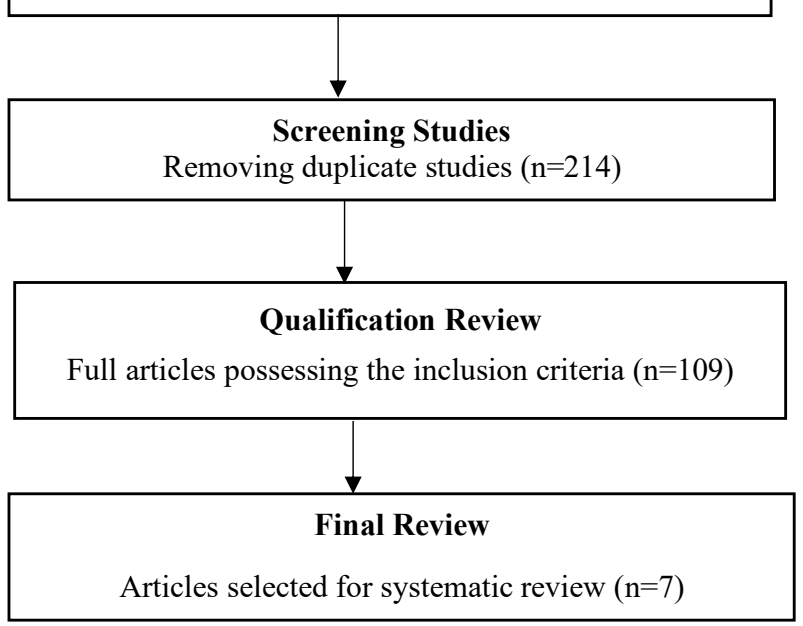

Figure 1. Diagram of Study Selection.

the intervention, judgment methods of the 7 articles. The result of our study demonstrated that different MI methods (i.e., face to face interviews, consultation sessions or calls, and educational programs) can effectively improve cervical cancer screening behavior in women. MIs in the assessed articles were categorized into two groups.

Some studies were conducted using motivational interviewing and motivational phone calls. For example, Mahmoudi Majd Abadi et al reported that $77.8 \%$ of women took a Pap smear test after five group motivational interviewing sessions compared to vs. $11 \%$ of the control group (11). According to Pourebrahim et al, 32\% and 22\% of women performed a Pap smear test after three group motivational interviewing sessions, three motivational phone calls, and $4 \%$ of women in the control group (12). In a study conducted by Zolfaghari et al, $20.9 \%$ of participants in the intervention group vs. $9 \%$ in the control group performed a Pap smear after three motivational

Table 1. Characteristic of Article Based on the Cochrane Risk of the Bias Tool

\begin{tabular}{|c|c|c|c|c|c|c|c|}
\hline \multirow[b]{2}{*}{ Author } & \multicolumn{2}{|c|}{ Selection Bias } & \multirow{2}{*}{$\begin{array}{c}\text { Performance Bias } \\
\text { Blinding } \\
\text { (participants and } \\
\text { personnel) }\end{array}$} & \multirow{2}{*}{$\begin{array}{c}\text { Attrition Bias } \\
\text { Incomplete } \\
\text { outcome data }\end{array}$} & \multirow{2}{*}{$\begin{array}{c}\begin{array}{c}\text { Reporting } \\
\text { Bias }\end{array} \\
\begin{array}{c}\text { Selective } \\
\text { reporting }\end{array}\end{array}$} & \multirow{2}{*}{$\begin{array}{c}\begin{array}{c}\text { Detection } \\
\text { Bias }\end{array} \\
\begin{array}{c}\text { Blinding } \\
\text { (outcome }\end{array} \\
\text { assessment) }\end{array}$} & \multirow{2}{*}{$\begin{array}{c}\text { Other Bias } \\
\begin{array}{c}\text { Other } \\
\text { sources of } \\
\text { bias }\end{array}\end{array}$} \\
\hline & $\begin{array}{c}\text { Random } \\
\text { sequence } \\
\text { generation }\end{array}$ & $\begin{array}{c}\text { Allocation } \\
\text { concealment }\end{array}$ & & & & & \\
\hline $\begin{array}{l}\text { Mahmoudi Majd Abadi et } \\
\text { al (2018) }\end{array}$ & Low risk & Low risk & Unclear & Low risk & Low risk & Unclear & Unclear \\
\hline Pourebrahim et al (2019) & Low risk & Low risk & Unclear & Low risk & High risk & Unclear & Unclear \\
\hline Dehdari (2014) & Low risk & Unclear & Unclear & Low risk & Low risk & Unclear & Unclear \\
\hline Ghahremani (2016) & Low risk & Unclear & Unclear & Low risk & Low risk & Unclear & Unclear \\
\hline Khiyali (2017) & Low risk & Unclear & Unclear & Low risk & Low risk & Unclear & Unclear \\
\hline Malmir (2018) & Low risk & Low risk & Unclear & Low risk & Low risk & Unclear & Unclear \\
\hline Zolfaghari (2018) & Low risk & Low risk & Unclear & Low risk & Low risk & Unclear & Unclear \\
\hline
\end{tabular}




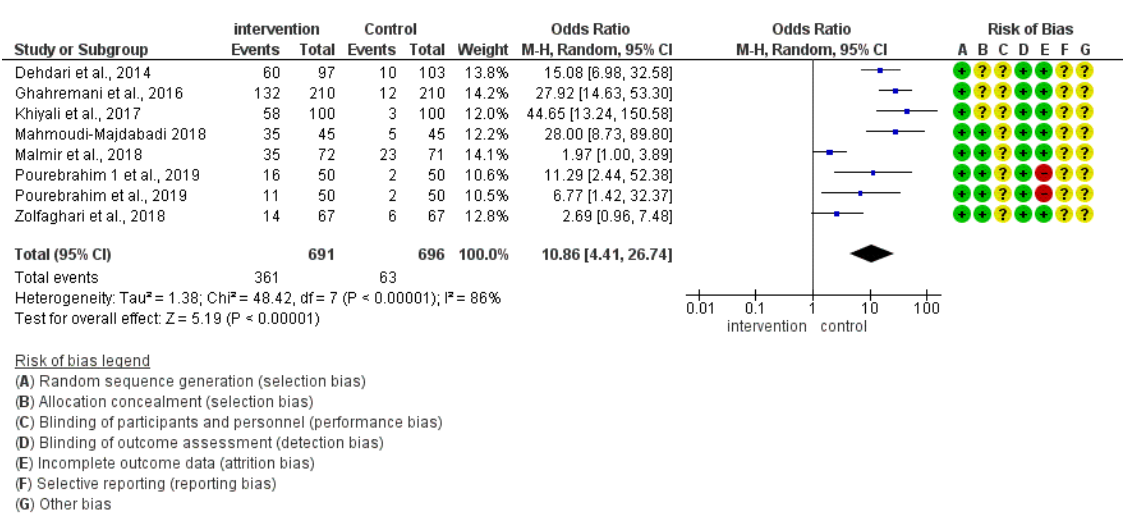

Figure 2. Forest Plot and Diagram of Bias in the Included Studies.

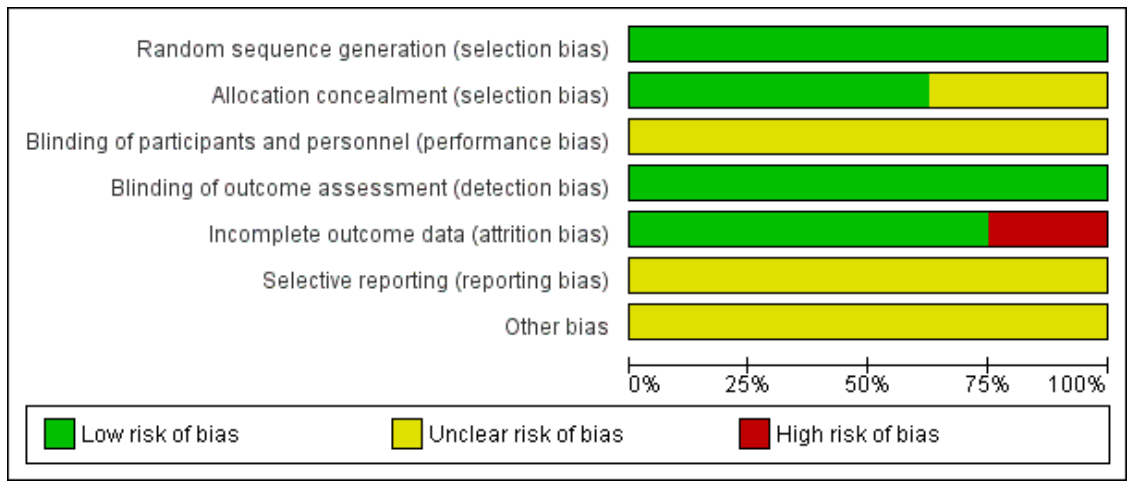

Figure 3. Risk of Bias Graph: Review Authors' Judgments About Each Risk of the Bias Item Presented as Percentages Across All Included Studies

interviewing sessions (13).

Other types of MI studies were educational interventions based on the protection motivation theory (PMT). For instance, Dehdari et al reported that $60 \%$ of women uptake Pap smear vs $10 \%$ of the control group after receiving education based on PMT (14). According to Malmir et al, $48.6 \%$ of women underwent a Pap smear test vs. $32.4 \%$ of the control group after the PMT-based intervention (15). In another study by Ghahremani et al, the rate of the Pap smear test in the intervention and control group was $62.85 \%$ vs. $5.7 \%$ after the PMT-based intervention (16). Similarly, Khiyali et al, (17) showed a significant difference in the rate of performing Pap smear in the experimental group (58\%) compared to the control group (3\%). Table 3 presents the difference between motivational-based intervention and control groups.

The study results suggested that both motivational interviewing and educational interventions based on PMT were effective in motivating women to perform a Pap smear.

\section{Discussion}

Cervical cancer is a common women cancer, and our study systematically assessed the effect of MIs on improving cervical cancer screening in women. A review of the literature revealed that few studies have focused on the effect of MIs on cancer screening behaviors. Based on the results of this systematic review, the motivationally tailored interventions are effective methods for boosting motivation regarding performing a Pap smear test. The evidence indicated that MIs could help reduce the barriers of cervical cancer screening and thus could help increase the cervical cancer screening rate.

The result of our study further showed that different MI methods (i.e., face-to-face interviews, consultation sessions or calls, and educational programs) are effective in cervical cancer screening uptake in women. In their systematic review, Lu et al reported that the combination of workplace-based educational programs with mobile screening services is effective in promoting breast and cervical cancer screening uptake in Asian women (18). In addition, Soares and Silva found that the use of media, telephone call, and invitation letter could increase women's knowledge about cervical cancer screening (19). Two other systematic reviews reported that one-to-one education and a reduction in constructive barriers could improve cervical cancer screening behavior $(20,21)$.

\section{Conclusions}

In conclusion, according to our systematic review, MIbased interventions were effective for improving cervical cancer screening and most relevant studies recommended using this type of interventions to increase the frequency of regular screening. It is noteworthy that MIs involve 
Table 3. Frequency of Pap Smear in Study Participants

\begin{tabular}{|c|c|c|c|c|c|}
\hline Author & $\begin{array}{l}\text { Applied Motivational } \\
\text { Strategy }\end{array}$ & Participants & $\begin{array}{l}\text { Frequency of Pap Smear } \\
\text { in the Intervention } \\
\text { Group }\end{array}$ & $\begin{array}{l}\text { Frequency of Pap } \\
\text { Smear in the Control } \\
\text { Group }\end{array}$ & $P$ Value \\
\hline $\begin{array}{l}\text { Mahmoudi Majd } \\
\text { Abadi (2018) }\end{array}$ & $\begin{array}{l}\text { Counseling based } \\
\text { on motivational } \\
\text { interviewing }\end{array}$ & $\begin{array}{l}90 \text { women (between } 30 \text { and } 59 \\
\text { years) in two groups (control and } \\
\text { intervention) each including } 45 \\
\text { subjects }\end{array}$ & $77.8 \%$ & $11.1 \%$ & 0.004 \\
\hline Zolfaghari et al & $\begin{array}{l}\text { Motivational } \\
\text { interviewing based } \\
\text { counseling }\end{array}$ & $\begin{array}{l}134 \text { teachers (aged } 30-60 \text { years) in } \\
\text { two groups (control and intervention) } \\
\text { each including } 67 \text { subjects }\end{array}$ & $20.9 \%$ & $9 \%$ & $<0.001$ \\
\hline $\begin{array}{l}\text { Pourebrahim } \\
\text { et al }\end{array}$ & $\begin{array}{l}\text { Motivational } \\
\text { interviewing based } \\
\text { counseling }\end{array}$ & $\begin{array}{l}150 \text { female (aged } 30-59 \text { years) in } \\
\text { three groups (i.e., motivational } \\
\text { interviewing, motivational phone } \\
\text { call, and control) each containing } 50 \\
\text { subjects }\end{array}$ & $\begin{array}{l}32 \% \text { in the motivational } \\
\text { interviewing group and } \\
22 \% \text { in the motivational } \\
\text { phone call group }\end{array}$ & $4 \%$ & 0.002 \\
\hline Dehdari et al & $\begin{array}{l}\text { Educational } \\
\text { intervention based } \\
\text { on the protection } \\
\text { motivation theory }\end{array}$ & $\begin{array}{l}200 \text { women in control ( } \mathrm{n}=103 \\
\text { with a mean age of } 37.9 \text { years) and } \\
\text { intervention ( } \mathrm{n}=97 \text { with a mean age } \\
\text { of } 38.8 \text { years) groups }\end{array}$ & $60 \%$ & $10 \%$ & $<0.001$ \\
\hline $\begin{array}{l}\text { Ghahremani } \\
\text { et al }\end{array}$ & $\begin{array}{l}\text { Educational } \\
\text { intervention based } \\
\text { on the protection } \\
\text { motivation theory }\end{array}$ & $\begin{array}{l}420 \text { women in control }(\mathrm{n}=210 \text { with } \\
\text { a mean age of } 37.09 \text { years) and } \\
\text { intervention ( } \mathrm{n}=210 \text { with a mean age } \\
\text { of } 38 \text { years) groups }\end{array}$ & $62.85 \%$ & $5.7 \%$ & $<0.001$ \\
\hline Khiyali et al & $\begin{array}{l}\text { Educational program } \\
\text { based on the } \\
\text { protection motivation } \\
\text { theory }\end{array}$ & $\begin{array}{l}200 \text { women in control }(\mathrm{n}=100 \\
\text { with a mean age } 36.76 \text { years) and } \\
\text { intervention ( } \mathrm{n}=100 \text { with a mean age } \\
\text { of } 37.82 \text { years) groups }\end{array}$ & $58 \%$ & $3 \%$ & $<0.001$ \\
\hline Malmir et al & $\begin{array}{l}\text { Educational } \\
\text { intervention based } \\
\text { on the protection } \\
\text { motivation theory }\end{array}$ & $\begin{array}{l}143 \text { women }(20-50 \text { years }) \text { in } \\
\text { intervention }(n=72) \text { and control }(n= \\
\text { 71) groups }\end{array}$ & $48.6 \%$ & $32.4 \%$ & 0.048 \\
\hline
\end{tabular}

strategies that increase one's motivation to move from the pre-contemplation and contemplation stages toward action and maintenance stages. Therefore, the use of MI strategies facilitates making decisions on change by taking into account the positive and negative aspects of a change $(22,23)$.

\section{Authors' Contribution}

The first, second, and third authors performed an initial search of databases and were major contributors in writing the manuscript. Fourth and fifth authors reviewed studies to investigate eligibility criteria. The sixth author regulated methods and performed a meta-analysis. All authors read and approved the final manuscript.

\section{Conflict of Interests}

Authors declare that they have no conflict of interests.

\section{Ethical Issues}

Not applicable.

\section{Financial Support}

This research was supported by Tabriz University of Medical Sciences financially as the one of the papers for MSC thesis (Grant, 1397.853) at faculty of Nursing and Midwifery at Tabriz University of Medical Sciences.

\section{Supplementary Materials}

Supplementary file 1 contains Table S1.

\section{References}

1. Fitzmaurice C, Dicker D, Pain A, et al. The global burden of cancer 2013. JAMA Oncol. 2015;1(4):505-527. doi:10.1001/ jamaoncol.2015.0735

2. Arbyn M, Rebolj M, De Kok IM, et al. The challenges of organising cervical screening programmes in the 15 old member states of the European Union. Eur J Cancer. 2009;45(15):2671-2678. doi:10.1016/j.ejca.2009.07.016

3. Ma GX, Toubbeh JI, Wang MQ, Shive SE, Cooper L, Pham A. Factors associated with cervical cancer screening compliance and noncompliance among Chinese, Korean, Vietnamese, and Cambodian women. J Natl Med Assoc. 2009;101(6):541-551. doi:10.1016/s0027-9684(15)30939-1

4. Anttila A, Pukkala E, Söderman B, Kallio M, Nieminen P, Hakama $M$. Effect of organised screening on cervical cancer incidence and mortality in Finland, 1963-1995: recent increase in cervical cancer incidence. Int J Cancer. 1999;83(1):59-65. doi:10.1002/ (sici)1097-0215(19990924)83:1<59::aid-ijc12>3.0.co;2-n

5. Saberi F, Sadat Z, Abedzadeh Kalahroudi M. Factors related to cervical cancer screening and its barriers in women. Payesh. 2012;11(3):351-356. [Persian].

6. Palacio A, Garay D, Langer B, Taylor J, Wood BA, Tamariz L. Motivational interviewing improves medication adherence: a systematic review and meta-analysis. J Gen Intern Med. 
2016;31(8):929-940. doi:10.1007/s11606-016-3685-3

7. Teixeira PJ, Palmeira AL, Vansteenkiste $M$. The role of selfdetermination theory and motivational interviewing in behavioral nutrition, physical activity, and health: an introduction to the IJBNPA special series. Int J Behav Nutr Phys Act. 2012;9:17. doi:10.1186/1479-5868-9-17

8. Rollnick S, Miller WR, Butler CC. Motivational Interviewing in Health Care: Helping Patients Change Behavior. New York, US: Guilford Press; 2008.

9. Mirkarimi K, Mostafavi F, Eshghinia S, Vakili MA, Ozouni-Davaji $\mathrm{RB}$, Aryaie M. Effect of motivational interviewing on a weight loss program based on the protection motivation theory. Iran Red Crescent Med J. 2015;17(6):e23492. doi:10.5812/ircmj.23492v2

10. Schoo AM, Lawn S, Rudnik E, Litt JC. Teaching health science students foundation motivational interviewing skills: use of motivational interviewing treatment integrity and self-reflection to approach transformative learning. BMC Med Educ. 2015;15:228. doi:10.1186/s12909-015-0512-1

11. Mahmoudi Majd Abadi M, Vakilian K, Safari V. Motivational interview on having Pap test among middle-aged women-a counseling service in primary care. Fam Med Prim Care Rev. 2018;20(2):101-105. doi:10.5114/fmpcr.2018.76457

12. Pourebrahim P. Effect of Motivational Interviewing and Motivational Phone Call on Performing a Pap Smear: A Randomized Controlled Trial. [thesis]. Tabriz: Faculty of Nursing and Midwifery, Tabriz University of Medical Sciences; 2019.

13. Zolfaghari Z, Rezaee N, Shakiba M, Navidian A. Motivational interviewing-based training vs traditional training on the uptake of cervical screening: a quasi-experimental study. Public Health. 2018;160:94-99. doi:10.1016/j.puhe.2018.04.007

14. Dehdari T, Hassani L, Hajizadeh E, Shojaeizadeh D, Nedjat S, Abedini M. Effects of an educational intervention based on the protection motivation theory and implementation intentions on first and second pap test practice in Iran. Asian Pac J Cancer Prev. 2014;15(17):7257-7261. doi:10.7314/apjcp.2014.15.17.7257

15. Malmir S, Barati M, Khani Jeihooni A, Bashirian S, Hazavehei SMM. Effect of an educational intervention based on protection motivation theory on preventing cervical cancer among marginalized women in west Iran. Asian Pac J Cancer Prev. 2018;19(3):755-761. doi:10.22034/apjcp.2018.19.3.755

16. Ghahremani L, Khiyali Harami Z, Kaveh MH, Keshavarzi S. Investigation of the role of training health volunteers in promoting pap smear test use among Iranian women based on the protection motivation theory. Asian Pac J Cancer Prev. 2016;17(3):11571162.

17. Khiyali Harami Z, Ghahremani L, Kaveh MH, Keshavarzi S. The effect of an educational program based on protection motivation theory on pap smear screening behavior among women referring to health centers in Fasa. Journal of Education and Community Health. 2017;3(4):31-37. doi:10.21859/jech.3.4.31

18. Lu M, Moritz S, Lorenzetti D, Sykes L, Straus S, Quan H. A systematic review of interventions to increase breast and cervical cancer screening uptake among Asian women. BMC Public Health. 2012;12:413. doi:10.1186/1471-2458-12-413

19. Soares MB, Silva SR. Interventions that facilitate adherence to Pap smear exam: integrative review. Rev Bras Enferm. 2016;69(2):404414. doi:10.1590/0034-7167.2016690226i

20. Spadea T, Bellini S, Kunst A, Stirbu I, Costa G. The impact of interventions to improve attendance in female cancer screening among lower socioeconomic groups: a review. Prev Med. 2010;50(4):159-164. doi:10.1016/j.ypmed.2010.01.007

21. Baron RC, Rimer BK, Coates RJ, et al. Methods for conducting systematic reviews of evidence on effectiveness and economic efficiency of interventions to increase screening for breast, cervical, and colorectal cancers. Am J Prev Med. 2008;35(1 Suppl):S26-33. doi:10.1016/j.amepre.2008.04.003

22. Alizadeh Sabeg P, Mehrabi E, Nourizadeh R, Poursharifi H, Mousavi S. The effect of counseling on breast cancer awareness in rural Iranian women: a randomized controlled clinical trial. J Cancer Educ. 2019;34(6):1083-1091. doi:10.1007/s13187-0181411-z

23. Azami S, Nourizadeh R, Mehrabi E, Poursharifi H, Farshbaf-Khalili A. Effect of motivational interviewing on dietary intake and weight changes among preconception women with overweight and obesity: a randomized controlled tria. Crescent J Med Biol Sci. 2020;7(2):260-266.

(C) 2021 The Author(s); This is an open-access article distributed under the terms of the Creative Commons Attribution License (http:// creativecommons.org/licenses/by/4.0), which permits unrestricted use, distribution, and reproduction in any medium, provided the original work is properly cited. 